\title{
ESTRUTURA DE UMA FLORESTA BREJOSA EM SUBSTRATO TURFOSO, SUL DE SANTA CATARINA, BRASIL ${ }^{1}$
}

Rafael Martins ${ }^{2}$, João André Jarenkow ${ }^{3}$, Eduardo Luís Hettwer Giehl ${ }^{4}$,Vanilde Citadini-Zanette ${ }^{2}$ e Robson dos Santos $^{2}$

\begin{abstract}
RESUMO - Objetivou-se descrever a diversidade e a estrutura do componente lenhoso de uma floresta brejosa em substrato turfoso no sul do Estado de Santa Catarina, correlacionando dados florísticos com variáveis ambientais. Indivíduos com DAP $\geq 5 \mathrm{~cm}$ foram amostrados em 100 parcelas de 10 x $10 \mathrm{~m}$ em um quadrado permanente de 1 ha. As variáveis ambientais foram classificadas em topográficas, químicas e texturais do solo e de luminosidade. Correlações espécie-ambiente foram obtidas por Análise de Correspondência Canônica (CCA). Comparações florísticas foram realizadas por análise de agrupamento (UPGMA) e análise de correspondência. A diversidade específica foi considerada baixa, pois foram amostradas apenas 26 espécies. A CCA evidenciou que as variáveis ambientais mensuradas possuem pouca influência na distribuição das espécies, ressaltando assim sua adaptação ao ambiente anóxico, fortemente limitante. Dados de similaridade demonstraram que o substrato turfoso age como um filtro ambiental adicional, além do estresse hídrico, na composição de espécies nas formações turfosas/ brejosas.
\end{abstract}

Palavras-chave: Mata Atlântica, Organossolos, Relação planta e ambiente.

\section{STRUCTURE OF A SWAMP FORESTS ON PEAT SUBSTRATES, SOUTH OF SANTA CATARINA, BRAZIL}

\begin{abstract}
This study aimed to describe the diversity and structure of woody vegetation of a swamp forests on peat substrate in the southern state of Santa Catarina, correlating floristic data with environmental variables. Individuals with $\mathrm{DBH} \geq 5 \mathrm{~cm}$ were sampled in 100 plots of $10 \times 10 \mathrm{~m}$ in one hectare squared plot. Environmental variables are classified in topographical, chemical and soil texture and light availability. Species-environment correlations were obtained by Canonical Correspondence Analysis (CCA). Floristic comparisons were performed by cluster (UPGMA) and correspondence analysis. Diversity was considered low because of the occurrence only 26 species in the whole sample. The CCA revealed that the measured variables have little influence on the distribution of species, highlighting the adaptation of these strong limiting environment. Similarity data showed that the peat substrate acts as an additional environmental filter beyond water stress to define species composition in Peat formations.
\end{abstract}

Keywords: Atlantic forest, Peat, Plant-Environment Relationship.

\footnotetext{
${ }^{1}$ Recebido em 13.06.2010 aceito para publicação em 05.04.2013.

${ }^{2}$ Programa de Pós-Graduação em Ciências Ambientais. Universidade do Extremo Sul Catarinense, UNESC, Brasil. E-mail:<rfm@unesc.net>, <vcz@unesc.net>e <rsa@unesc.net>.

${ }^{3}$ Departamento de Botânica, Universidade Federal do Rio Grande do Sul, UFRGS, Brasil. E-mail:<jarenkow @ portoweb.com.br>.

${ }^{4}$ Departamento de Botânica, Universidade Federal de São Carlos, UFSCAR, Brasil.E-mail:<eduardogiehl@ gmail.com>.
} 


\section{INTRODUÇÃO}

A variedade de ambientes do Domínio Atlântico favorece a existência de ecossistemas complexos, englobando a Floresta Pluvial Atlântica, a Floresta Estacional Semidecidual, mangues, restingas e campos de altitude (OLIVEIRA-FILHO; FONTES, 2000; SCUDELLER et al., 2001; SCARANO, 2002). Essa complexidade se reflete nos padrões de riqueza e diversidade encontrados em florestas tropicais, entre elas a Floresta Atlântica, que vem sendo objeto de muitos estudos no âmbito da ecologia vegetal.

As florestas higrófilas ou paludosas são ambientes floristicamente pobres, devido à saturação hídrica permanente a que as espécies estão submetidas (RODRIGUES, 1999). Florestas paludosas em substrato turfoso ocorrem em todas as zonas climáticas do planeta, geralmente em áreas costeiras, desenvolvendo-se em sedimentos flúvio-marinhos recentes ou em ambientes úmidos, de altitudes pouco mais elevadas. Em Santa Catarina, ocupam cerca de $0,12 \%$ da superfície do Estado, predominando nos municípios da planície costeira sul (SOUZA-JÚNIOR et al., 2001; POTTER et al., 2004). As formações da planície costeira, restingas e florestas brejosas são consideradas formações marginais da Floresta Atlântica. Mesmo assim, sua flora é composta de espécies originalmente atlânticas, o que pode indicar ampla plasticidade ecológica dessas espécies ou processos de adaptação (SCARANO, 2002, 2006).

Os ecossistemas de restinga têm recebido maior atenção nos estudos realizados na planície costeira sul, com destaque para as formações de restinga arenosa (DILLENBURG etal., 1992; ROSSONI; BAPTISTA, 1994, 1995; WAECHTER et al., 2000; MORAES;MONDIN, 2001; SCHERER et al., 2005). Poucos são os estudos em Florestas Turfosas, o que é atribuído à sua descontinuidade natural, assim como às atividades exploratórias para fins econômicos (DORNELLES; WAECHTER, 2004). Entre os poucos estudos realizados nessa formação, destacam-se os de Waechter e Jarenkow (1998) e Dorneles e Waechter (2004) no Rio Grande do Sul e Sztutman e Rodrigues (2002) em São Paulo. Em Santa Catarina, tal formação ainda é pouco estudada.

Visando ampliar o conhecimento sobre a vegetação da planície costeira sul, objetivou-se descrever a estrutura vegetacional de uma floresta brejosa em substrato turfoso no Sul do Estado de Santa Catarina, correlacionando dados florísticos com variáveis edáficas e de luminosidade.

\section{MATERIAL E MÉTODOS}

\section{1. Área de estudo}

A área de estudo compreendeu um remanescente florestal com área aproximada de 30 ha localizado no Município de Araranguá (2902'S e 49³1'W, Figura 1), denominado Floresta de Restinga Paludosa, ou Brejosa, sobre solo turfoso, a uma altitude variando de 3,3 a 3,9 m. O clima enquadra-se no tipo Cfa (subtropical úmido com verões quentes), segundo a classificação de Köppen(DUFLOTHetal., 2005). EmAraranguá (Estação Meteorológica de Araranguá: 2855'S, 49²9'W e 12,3 m de altitude), a média anual de precipitação é de 1.496 $\mathrm{mm}$, sendo fevereiro o mês mais chuvoso, com média mensal de 177 mm; e abril o mês menos chuvoso, com média mensal de $74 \mathrm{~mm}$. A temperatura média anual é $19,1^{\circ} \mathrm{C}$, sendo junho e julho os meses mais frios, com temperatura mínima média mensal de $11,2{ }^{\circ} \mathrm{C}$ e $10{ }^{\circ} \mathrm{C}$, respectivamente.

O solo predominante, de acordo com o Sistema Brasileiro de Classificação de Solos (EMBRAPA, 1999), é Organossolo. A área de estudo situa-se na unidade geomorfológica Planícies Litorâneas, abrangendo uma área de $4.212 \mathrm{~km}^{2}$ da porção oriental do Estado, no oceano Atlântico. A vegetação enquadra-se na região fitoecológica da Floresta Ombrófila Densa, com o componente arbóreo caracterizado pela baixa riqueza, com dominância ecológica de poucas espécies. O subbosque é caracterizado pela presença de Geonoma schottiana Mart. e o estrato herbáceo, com predomínio de Nidularium inocentii Lem. (dados não publicados).

\subsection{Amostragem da vegetação}

Para a amostragem, foi utilizado o método de parcelas (MUELLER-DOMBOIS; ELLENBERG, 2002), sendo demarcadas 100 unidades amostrais contíguas de 10 $\mathrm{x} 10 \mathrm{~m}$, em um quadrado permanente de 1 ha, nas quais foram amostrados todos os indivíduos arbóreos com diâmetros do caule à altura do peito (DAP), a 1,30 m do solo, igual ou maior $5 \mathrm{~cm}$. Além da medida do DAP, as alturas dos indivíduos foram também estimadas. Foram aqui desconsideradas espécies lenhosas de hábito epifítico e lianoso. Os trabalhos de campo ocorreram de setembro de 2007 a março de 2008.

Para delimitação de famílias, seguiram-se as propostas de APG III (2009). Na análise dos dados, foram utilizados os valores relativos dos seguintes descritores estruturais: frequência, densidade e 

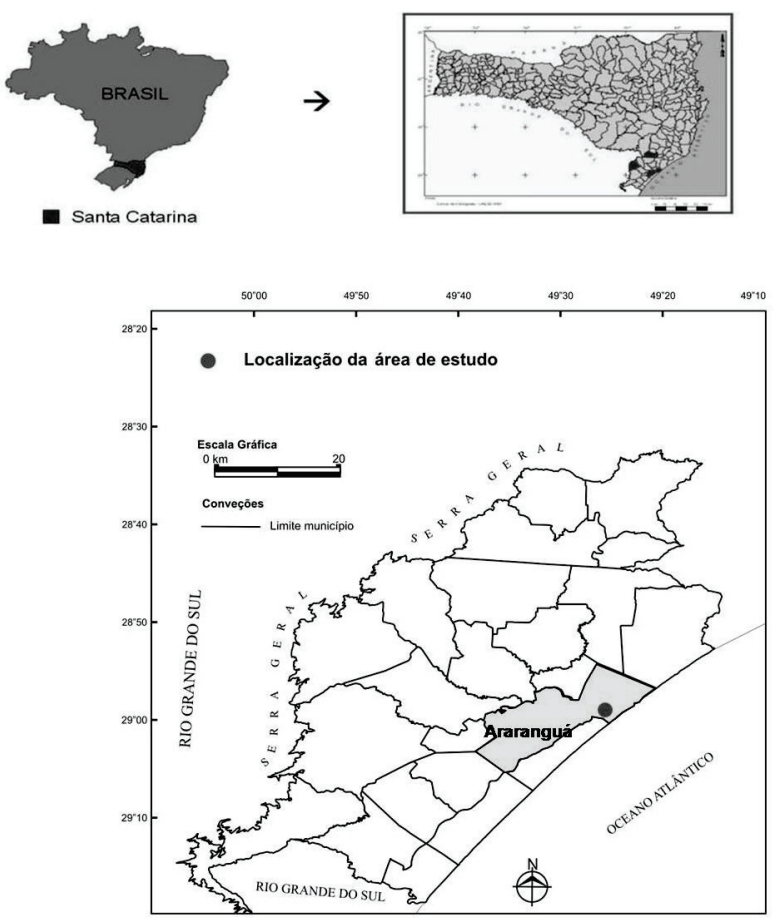

Figura 1 - Localização geográfica do Estado de Santa Catarina, com destaque ao município de Araranguá. Ponto indica a localização da área de estudo no respectivo município.

Figure 1 - Geographical location of the State of Santa Catarina, Highlights the city of Araranguá. Dot indicates the location of the study area in the respective municipality.

dominância, além do valor de importância. Para a análise da diversidade florística, foram utilizados os índices de Shannon (H') e o de equidade (J'), que são baseados na abundância proporcional das espécies.

\subsection{Amostragem de solo e de luminosidade}

O levantamento planialtimétrico de cada parcela foi executado extraindo-se duas variáveis topográficas de cada unidade amostral: cota média e desnível. O solo foi classificado em campo segundo o Sistema Brasileiro de Classificação de Solos (EMBRAPA, 1999). No centro de cada parcela, foram coletadas amostras de solo, com trado holandês, da superfície à profundidade de $20 \mathrm{~cm}$, depois de afastada a serapilheira. As análises compreenderam: $\mathrm{pH}$, fósforo, potássio, alumínio, cálcio, magnésio, sódio, $\mathrm{H}+\mathrm{Al}$, soma de bases, capacidade de troca de cátions (CTC) e saturação de bases (V). A incidência de luz (luminosidade) foi obtida por fotografias hemisféricas no centro de cada unidade amostral, a partir das quais foi estimado o percentual de abertura do dossel, com o auxílio do software Gap Light Analyzer - GLA 2.0 (FRAZER et al., 1999).

\subsection{Análise dos dados}

As correlações entre os dados ambientais e vegetacionais foram determinadas por análise de correspondência canônica (CCA) (TER BRAAK, 1987), utilizando o programa CANOCO 4.5 (TER BRAAK; SMILAUER, 2002). A matriz de abundância das espécies foi constituída pelo número de indivíduos por unidade amostral, nas espécies que apresentaram no mínimo 10 indivíduos. Os valores de abundância foram transformados pela expressão $\ln (\mathrm{x}+1)$ antes da ordenação, a fim de atenuar diferenças apenas nas abundâncias (TER BRAAK, 1995). A matriz de variáveis ambientais consistiu das 13 variáveis químicas e texturais do solo, duas variáveis topográficas (elevação e desnível) e luminosidade. As variáveis ambientais foram avaliadas quanto à relação com a matriz de espécies por meio de testes de permutação $(\alpha=0,05)$ e removidas em caso de não apresentarem associação significativa. As variáveis expressas em percentuais foram transformadas pela expressão arcosseno $(\sqrt{ } \mathrm{x} / 100)$.

A área de estudo foi comparada com a de diferentes estudos, por meio de análise de agrupamento hierárquico, pelo método da média aritmética não ponderada (UPGMA), tendo como medida de similaridade o índice de Jaccard. Uma Análise de Correspondência (CA) foi realizada para verificar a ocorrência de gradientes na ordenação das amostras (KENT; COKER, 1992), dispostas em um diagrama bidimensional. Os dados florísticos foram comparados com os de estudos realizados em florestas turfosas (WAECHTER; JARENKOW, 1998; SZTUTMAN; RODRIGUES, 2002; DORNELES; WAECHTER, 2004), paludosas com inundação permanente (ROCHA et al., 2005; TEIXEIRA; ASSIS, 2005; TEIXEIRA et al., 2008; TEIXEIRA; ASSIS, 2009), de restinga arenosa (SCHERER et al., 2005; SILVA, 2010) e de formações das terras baixas (SZTUTMAN; RODRIGUES, 2002; NEGRELLE, 2006), as duas últimas com o intuito de comparação florística com situações de solos bem drenados.

\section{RESULTADOS}

\subsection{Composição florística e estrutura vegetacional}

Foram identificadas 26 espécies, distribuídas em 21 gêneros e 15 famílias (Tabela 1). Myrtaceae apresentou maior número de espécies (cinco), seguida

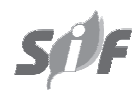

Revista Árvore, Viçosa-MG, v.37, n.2, p.299-309, 2013 
de Arecaceae e Urticaceae (três) e Aquifoliaceae, Moraceae e Primulaceae (duas). Os gêneros Myrcia, com três espécies; e Ilex e Myrsine, com duas, foram os de maior riqueza.
Foram amostrados 2.034 indivíduos, estando 63\% da densidade total concentrada em apenas três espécies, Ocotea pulchella, Myrcia pulchra e Myrcia multiflora, que também acumularam maior parte do valor de

Tabela 1 - Espécies, nas respectivas famílias, áreas basais $\left(\mathrm{AB} \mathrm{em} \mathrm{m}^{2}\right)$, densidade ( $\mathrm{D} \mathrm{em} \mathrm{ind.ha-1),} \mathrm{frequência} \mathrm{relativa} \mathrm{(FR \% ),}$ densidade relativa (DR\%), dominância relativa (DoR\%) e valores de importância (VI) correspondentes à amostragem da vegetação lenhosa em floresta brejosa em substrato turfoso, sul de Santa Catarina, Brasil.

Table 1 -Species, their botanical families, basal area $\left(A B\right.$ in $\left.\mathrm{m}^{2}\right)$, density $\left(D\right.$ ind.ha $\left.{ }^{-1}\right)$, relative frequency $(F R \%)$, relative density (DR\%), relative dominance (DoR\%) and importance values (VI) corresponding to the sampling of woody vegetation in swamp forests on peat substrate, south of Santa Catarina, Brazil.

\begin{tabular}{|c|c|c|c|c|c|c|}
\hline Família/Espécie & $\mathrm{AB}$ & $\mathrm{D}$ & DR & FR & DoR & VI \\
\hline \multicolumn{7}{|l|}{ Aquifoliaceae } \\
\hline Ilex dumosa Reissek & 0,006 & 1 & 0,05 & 0,16 & 0,02 & 0,23 \\
\hline \multicolumn{6}{|l|}{ Arecaceae } & 0,91 \\
\hline Euterpe edulis Mart. & 0,308 & 80 & 3,93 & 6,85 & 0,94 & 11,72 \\
\hline Geonoma schottiana Mart. & 0,044 & 15 & 0,74 & 2,39 & 0,14 & 3,26 \\
\hline $\begin{array}{l}\text { Syagrus romanzoffiana (Cham.) Glassman } \\
\text { Clusiaceae }\end{array}$ & \multicolumn{5}{|c|}{ Clusiaceae } & 4,09 \\
\hline $\begin{array}{l}\text { Clusia criuva Cambess. } \\
\text { Cunnoniaceae }\end{array}$ & 1,189 & 51 & 2,51 & 5,73 & 3,64 & 11,88 \\
\hline $\begin{array}{l}\text { Weinmannia paulliniifolia } \text { Pohl ex Ser. } \\
\text { Euphorbiaceae }\end{array}$ & 0,004 & 1 & 0,05 & 0,16 & 0,01 & 0,22 \\
\hline $\begin{array}{l}\text { Alchornea triplinervia (Spreng.) M. Arg. } \\
\text { Lauraceae }\end{array}$ & 2,514 & 72 & 3,54 & 8,76 & 7,70 & 20,00 \\
\hline $\begin{array}{l}\text { Ocotea pulchella (Nees) Mez } \\
\text { Malpighiaceae }\end{array}$ & 14,035 & 500 & 24,58 & 15,61 & 43,00 & 83,18 \\
\hline $\begin{array}{l}\text { Byrsonima ligustrifolia A. Juss. } \\
\text { Meliaceae }\end{array}$ & 1,854 & 205 & 10,08 & 9,08 & 5,68 & 24,83 \\
\hline $\begin{array}{l}\text { Guarea macrophylla Vahl } \\
\text { Moraceae }\end{array}$ & 0,017 & 6 & 0,29 & 0,80 & 0,05 & 1,14 \\
\hline Ficus cestrifolia Schott & 2,548 & 22 & 1,08 & 3,03 & 7,80 & 11,91 \\
\hline $\begin{array}{l}\text { Ficus luschnathiana (Miq.) Miq. } \\
\text { Myrtaceae }\end{array}$ & 0,056 & 1 & 0,05 & 0,16 & 0,17 & 0,38 \\
\hline Blepharocalyx salicifolius (Kunth) O.Berg & 0,087 & 15 & 0,74 & 1,59 & 0,27 & 2,60 \\
\hline Myrcia brasiliensis Kiaersk. & 0,011 & 1 & 0,05 & 0,16 & 0,03 & 0,24 \\
\hline Myrcia multiflora (Lam.) DC. & 4,054 & 352 & 17,31 & 11,62 & 12,42 & 41,35 \\
\hline Myrcia pulchra (O.Berg) Kiaersk. & 2,689 & 434 & 21,34 & 11,62 & 8,24 & 41,20 \\
\hline $\begin{array}{l}\text { Psidium cattleianum Sabine } \\
\text { Nyctaginaceae }\end{array}$ & 1,284 & 197 & 9,69 & 12,26 & 3,93 & 25,88 \\
\hline $\begin{array}{l}\text { Guapira opposita (Vell.) Reitz } \\
\text { Peraceae }\end{array}$ & 0,015 & 3 & 0,15 & 0,48 & 0,04 & 0,67 \\
\hline $\begin{array}{l}\text { Pera glabrata (Schott) Poepp. ex Baill. } \\
\text { Primulaceae }\end{array}$ & 0,006 & 2 & 0,10 & 0,32 & 0,02 & 0,44 \\
\hline Myrsine coriacea $(\mathrm{Sw}.) \mathrm{R} . \mathrm{Br}$. & 0,004 & 2 & 0,10 & 0,16 & 0,01 & 0,27 \\
\hline $\begin{array}{l}\text { Myrsine parvula }(\mathrm{Mez}) \text { Otegui } \\
\text { Salicaceae }\end{array}$ & 0,140 & 8 & 0,39 & 0,64 & 0,43 & 1,46 \\
\hline $\begin{array}{l}\text { Casearia sylvestris } \mathrm{Sw} . \\
\text { Urticaceae }\end{array}$ & 0,007 & 2 & 0,10 & 0,32 & 0,02 & 0,44 \\
\hline Cecropia pachystachya Trécul. & 0,046 & 5 & 0,25 & 0,64 & 0,14 & 1,02 \\
\hline Coussapoa microcarpa (Schott) Rizzini & 1,376 & 36 & 1,77 & 4,46 & 4,22 & 10,44 \\
\hline Urera nitida (Vell.) Brack & 0,005 & 1 & 0,05 & 0,16 & 0,02 & 0,22 \\
\hline & 32,644 & 2034 & 100,00 & 100,00 & 100,00 & 300,00 \\
\hline
\end{tabular}

Revista Árvore, Viçosa-MG, v.37, n.2, p.299-309, 2013 
importância VI (165). Aárea basal total foi de 32,644 m², com os valores de diâmetro à altura do peito (DAP) variando de 5,09 a 70,98 cm. Os maiores fustes foram apresentados por indivíduos de Ficus cestrifolia que, apesar da baixa densidade (22 indivíduos), ocuparam a sétima posição em termos de dominância. A distribuição diamétrica se enquadrou na distribuição de Poisson, amplamente reconhecida como "J invertido" (Figura 2), com grande parte dos indivíduos concentrados nas primeiras classes de diâmetro. Neste estudo, a altura variou de 2 a $14 \mathrm{~m}$, com valor modal de $7 \mathrm{~m}$ (Figura 2). Destacaram-se indivíduos de $F$. cestrifolia, $O$. pulchella e Alchornea triplinervia, com as maiores alturas.

A diversidade estimada pelo índice de Shannon (H') foi de 2,123 nats.ind. ${ }^{-1} \mathrm{e} o$ índice de equidade de Pielou (J), igual a 0,651. O dendrograma de similaridade aplicado a estudos realizados em florestas turfosas e paludosas com inundação permanente formou três grupos: formações turfosas, terras baixas e formações paludosas (Figura 3).
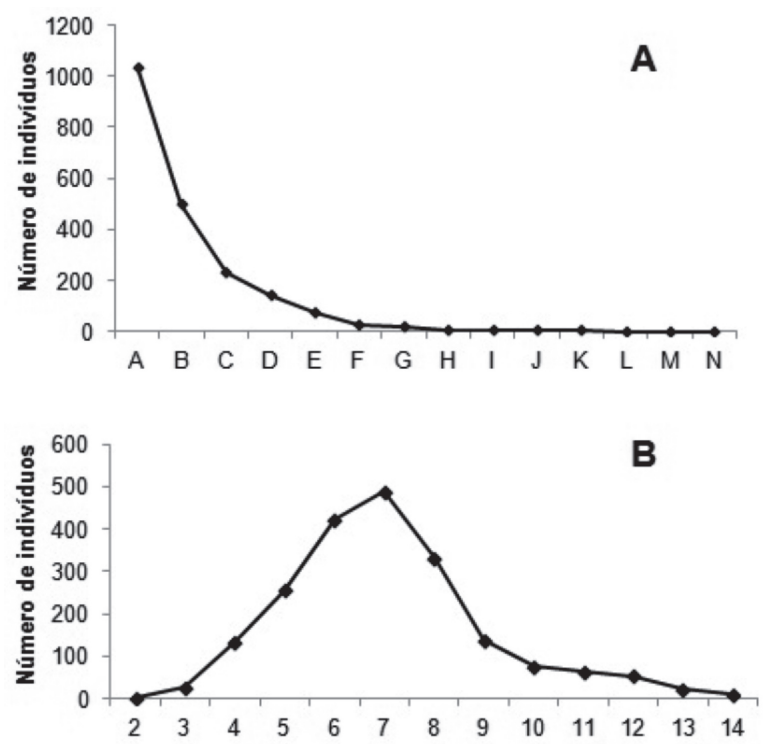

Figura 2 - A - distribuição do número de indivíduos amostrados por classes de diâmetro $(A=5-9,9 \mathrm{~cm}, \mathrm{~B}=10$ $14,9 \mathrm{~cm}, \ldots, \mathrm{N}=70-74,9 \mathrm{~cm}) ; \mathrm{B}$ - valores absolutos das alturas $(\mathrm{m})$ estimadas em floresta brejosa em substrato turfoso, sul de Santa Catarina.

Figure 2-A - distribution of number of individuals sampled by diameter classes of $5 \mathrm{~cm}(A=5-9,9 \mathrm{~cm}, B=$ $10-14,9 \mathrm{~cm}, \ldots, N=70-74,9 \mathrm{~cm}) ; B$ - absolute values of height $(m)$ estimated in swamp forests on peat substrate, south of Santa Catarina.

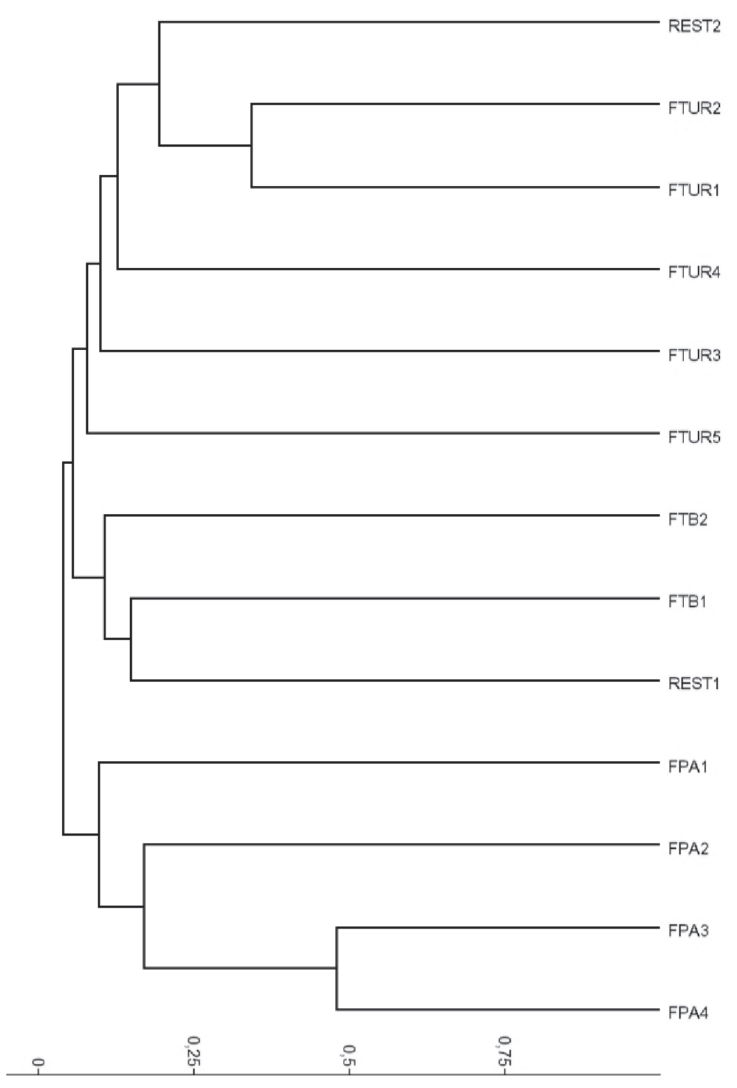

Figura 3 - Análise de agrupamento (UPGMA) de estudos realizados na floresta atlântica do sul e sudeste brasileiro, agrupados pelo índice de similaridade de Jaccard. Os códigos exibidos no diagrama correspondem: Presente estudo=FTUR1; Dorneles e Waechter (2004)=FTUR2; Negrelle (2006)=FTB1; Silva $(2010)=$ REST1; Rocha et al. $(2005)=$ FPA 1 ; Scherer et al. (2005)=REST2; Sztutman e Rodrigues (2002) em morrote=FTB2; Sztutman e Rodrigues (2002) em turfa profunda=FTUR3; Sztutman e Rodrigues (2002) em turfa rasa=FTUR4; Teixeira eAssis (2009)=FPA2; Teixeira e Assis (2005)=FPA3; Teixeira et al. (2008)=FPA4; Waechter e Jarenkow $(1998)=$ FTUR5.

Figure 3 - Cluster analysis (UPGMA) from studies in Atlantic forest of southern and southeastern Brazil, grouped by the similarity index of Jaccard. The codes shown in the diagram correspond: This study $=$ FTUR1; Dorneles and Waechter $(2004)=$ FTUR $2 ;$ Negrelle $(2006)=$ FTB $1 ;$ Silva $(2010)=$ REST1; Rocha et al. $(2005)=$ FPA 1 ; Scherer et al. $(2005)=$ REST2; Sztutman and Rodrigues (2002) in low land = FTB2; Sztutman and Rodrigues (2002) in deep peat = FTUR3; Sztutman and Rodrigues (2002) in shallow peat $=$ FTUR4; Teixeira and Assisi (2009) $=$ FPA2; Teixeira and Assis (2005) = FPA3; Teixeira et al. $(2008)=$ FPA4; Jarenkow and Waechter $(1998)=$ FTUR5.

Revista Árvore, Viçosa-MG, v.37, n.2, p.299-309, 2013 


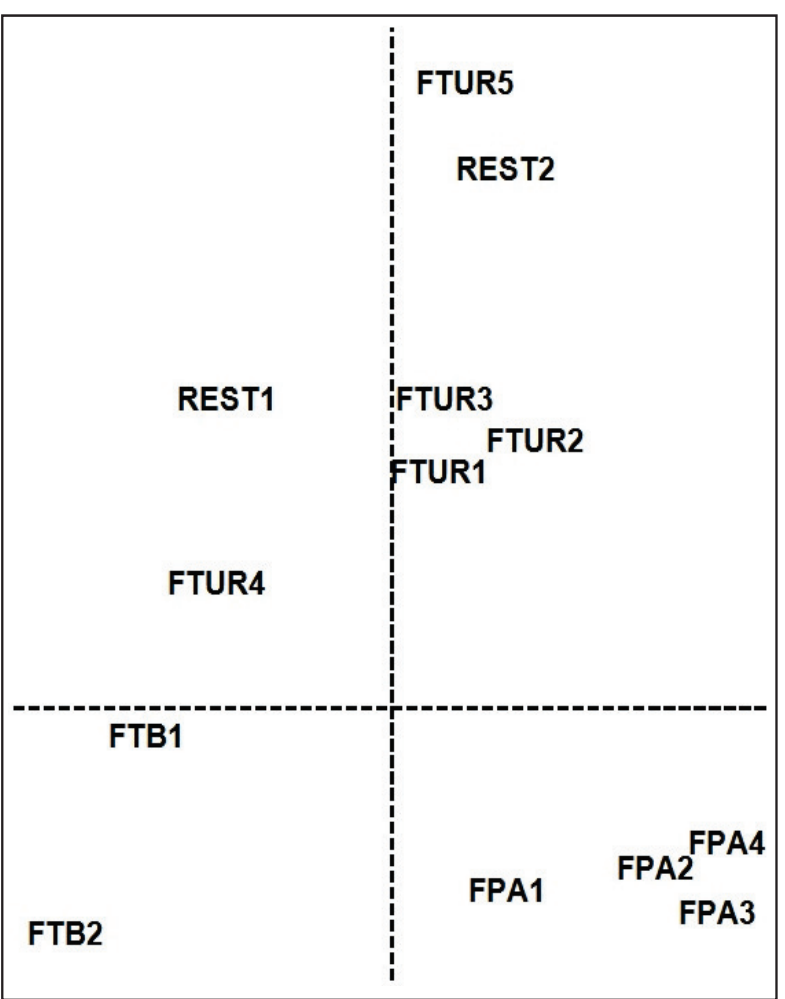

Figura 4 - Diagrama de ordenação, produzido por análise de correspondência, dos estudos realizados naFloresta Atlântica do sul e sudeste brasileiro (eixo $1=13,7 \%$ e eixo $2=12,9 \%$ de variância explicada). Presente estudo=FTUR1; Dorneles e Waechter $(2004)=$ FTUR 2 ; Negrelle $(2006)=$ FTB 1 ; Silva $(2010)=$ REST $1 ;$ Rocha et al. $(2005)=$ FPA 1 ; Scherer et al. (2005) = REST2; Sztutman e Rodrigues (2002) em morrote $=$ FTB2; Sztutman e Rodrigues (2002) em turfa profunda = FTUR3; Sztutman e Rodrigues (2002) em turfa rasa =FTUR4; Teixeira e Assis (2009) = FPA2; Teixeira e Assis (2005) = FPA3; Teixeira et al. $(2008)=$ FPA4; Waechter e Jarenkow (1998) = FTUR5.

Figure 4-Diagram of ordination produced by correspondence analysis of studies conducted in the southern and southeastern Brazil Atlantic forests (axis $1=13,7$ and axis $2=12,9 \%$ of variance explained). The codes shown in the diagram correspond: This study = FTUR1; Dorneles and Waechter (2004) = FTUR2; Negrelle $(2006)=$ FTB1; Silva $(2010)=$ REST1; Rocha et al. $(2005)=$ FPA1; Scherer et al. (2005) $=$ REST2; Sztutman and Rodrigues (2002) in low land = FTB2; Sztutman and Rodrigues (2002) in deep peat = FTUR3; Sztutman and Rodrigues (2002) in shallow peat $=$ FTUR4; Teixeira and Assisi (2009) = FPA2; Teixeira and Assis $(2005)=$ FPA3; Teixeira et al. $(2008)=$ FPA4; Jarenkow and Waechter (1998) $=$ FTUR5.
A análise de correspondência aplicada à matriz que continha os dados dos estudos destacados antes mostrou separação das áreas nos dois primeiros eixos de ordenação (Figura 4).

Embora a Análise de Correspondência (AC) seja considerada técnica descritiva e exploratória, seu uso simplifica dados complexos e produz informações que suportam conclusões sobre o tema em estudo. Assim, pode-se determinar o gradiente edáfico separando os estudos de florestas brejosas em solo turfoso (FTUR) daqueles de solo apenas brejoso (FPA).

\subsection{Relação das espécies com variáveis ambientais}

$\mathrm{O}$ pH apresentou-se muito baixo $(3,50 \pm 0,18)$, caracterizando solos extremamente ácidos. Cátions essenciais como $\mathrm{Ca}^{+2}, \mathrm{Mg}^{+2}$ e $\mathrm{K}^{+}$tiveram valores altos $(6,67(\mathrm{cmolc} / \mathrm{L}) \pm 1,46 ; 3,40(\mathrm{cmolc} / \mathrm{L}) \pm 0,65$ e 71,63 $(\mathrm{ppm}) \pm 28,55$ respectivamente), refletindo nos valores da soma de bases $(\mathrm{S}=10,86(\mathrm{cmolc} / \mathrm{L}) \pm 1,89)$. A saturação por bases $(\mathrm{V}=8,08(\%) \pm 3,14)$ foi considerada baixa, ao passo que a acidez potencial $(\mathrm{H}+\mathrm{Al}=133,10(\mathrm{cmolc} / \mathrm{L})$ $\pm 34,62$ ), muito alta. A intensidade luminosa nas parcelas, dada pela abertura do dossel, foi de $12,96 \% \pm 3,13$. Com relação às variáveis topográficas, a elevação média foi de 3,63 m \pm 0,11 e o desnível médio, de 0,07 $\mathrm{m} \pm$ 0,06 .

Os autovalores, assim como a variância acumulada, foram baixos $(0,070$ e 0,008 , respectivamente, para os dois primeiros eixos) e $8,5 \%$ de variância explicada. As correlações dos dois primeiros eixos foram de 0,56 e 0,28 , respectivamente. As correlações ponderadas indicaram relação negativa entre acidez potencial $(\mathrm{H}$ + Al), alumínio e saturação por bases (V) e pH. Essa relação define a tolerância das espécies aos menores valores de $\mathrm{pH}$ e saturação por bases e maior acidez potencial, evidenciado nos valores de correlação apenas com o primeiro eixo de ordenação $(P>0,001)$.

\section{DISCUSSÃO}

A baixa riqueza apresentada pode ser atribuída à condição edáfica local, o que também foi verificado em florestas brejosas em substrato turfoso no Sul do Brasil (WAECHTER; JARENKOW, 1998; DORNELES; WAECHTER, 2004), que igualmente obtiveram baixa riqueza. A limitação imposta pelo substrato é evidenciada à medida que a saturação hídrica diminui, em que se tem registrado aumento na riqueza, como observado 
em formações arenosas de restinga no Rio Grande do Sul (SCHERER et al., 2005) e em formações das terras baixas (NEGRELLE, 2006), onde foram observadas 31 e 128 espécies, respectivamente. Essa baixa riqueza específica, acompanhada de alta dominância ecológica nesses ambientes, pode constituir padrão em florestas tropicais (FÉDOROFF et al., 2005).

O destaque de Myrtaceae é evidente não só em formações brejosas (WAECHTER; JARENKOW, 1998; SZTUTMAN; RODRIGUES, 2002; DORNELES; WAECHTER, 2004), como também em diversas formações vegetais do Sul e Sudeste do Brasil (NEGRELLE, 2003; SCHERER et al., 2005; NEGRELLE, 2006; CARVALHO et al., 2008), o que denota a importância ecológica dessa família na Mata Atlântica e pode indicar ainda, pelo destaque em formações brejosas, adaptação dessas espécies à saturação hídrica (SILVA et al., 2009).

As demais famílias com destaque neste estudo (Urticaceae, Arecaceae, Aquifoliaceae e Moraceae) também aparecem com evidência nas formações turfosas do Rio Grande do Sul (WAECHTER; JARENKOW, 1998; DORNELES; WAECHTER, 2004) e São Paulo (SZTUTMAN; RODRIGUES, 2002). Entretanto, em formações paludosas com ausência de substrato turfoso evidencia-se, além de maior riqueza específica, maior número de famílias amostradas (TEIXEIRA; ASSIS, 2005; ROCHA et al., 2005; TEIXEIRA et al., 2008). Os valores de densidade refletem o processo de dominância ecológica, caracterizado pela baixa riqueza e elevada abundância, como constatado em $O$. pulchella, $M$. multiflora e M. pulchra, que totalizaram $63 \%$ dos indivíduos amostrados, com reflexo nos valores de diversidade (WAECHTER; JARENKOW, 1998; SCARANO, 2002; SZTUTMAN; RODRIGUES, 2002; ROCHA et al., 2005).

A distribuição diamétrica deve ser interpretada com cautela, principalmente quando associadas aos termos "populações estáveis", "autorregenerativas", "balanço mortalidade-recrutamento" (LOPES et al., 2002). Verifica-se que a maior densidade nas classes iniciais de diâmetro compreendem espécies do interior de floresta como M. pulchra, M. multiflora, B. ligustrifolia e E. edulis. Assim, o "J invertido" deve ser interpretado como resultado de características estruturais da comunidade, somado a aspectos biológicos das espécies, e não de atributos isolados de populações.
A predominância de espécies do estrato inferior em classes iniciais de diâmetro pode estar relacionada à estruturação vertical da floresta, que, quanto mais compartimentalizada, tende à maior diversidade (GUILHERME et al., 2004). A área de estudo apresenta baixa compartimentalização (Figura 2), possivelmente por sua homogeneidade ambiental. Essa estruturação vertical caracteriza o interior da floresta sob o dossel de $O$. pulchella, podendo se estabelecer uma estratificação em compartimentos superior (dossel) e inferior, este último com espécies do interior de floresta, como $M$. multiflora e $M$. pulchra, associadas à presença de Geonoma schottiana, palmeira típica do sub-bosque, com baixa abundância neste estudo devido ao critério de inclusão.

A dominância ecológica observada nas formações brejosas gera estratificação que diverge do padrão descrito para a Mata Atlântica, que, segundo Veloso e Klein (1957), apresenta três estratos lenhosos (árvores, arvoretas e arbustos) bastante desenvolvidos e densos, acompanhados de um herbáceo bastante diversificado.

A diversidade arbórea estimada pelo índice de Shannon $\left(H^{\prime}=2,123\right)$ se mostrou próxima à encontrada em estudo realizado na floresta turfosa do Parque Nacional da Lagoa do Peixe em Mostardas/Tavares, RS (H'=2,601 DORNELES; WAECHTER, 2004) e sobre a restinga de Pariquera-Açu, SP $\left(\mathrm{H}^{\prime}=2,98-\right.$ SZTUTMAN; RODRIGUES, 2002). As diferenças obtidas em relação o estudo de Waechter e Jarenkow (1998) $\left(\mathrm{H}^{\prime}=1,886\right)$ podem ser atribuídas ao critério de inclusão adotado por esses últimos autores (DAP $\geq 10 \mathrm{~cm}$ ).

A primeira causa de maior similaridade entre áreas (padrão geográfico) deve-se à proximidade entre as formações turfosas sul-rio-grandenses e a área deste estudo, associada a suas condições ambientais similares (clima, temperatura, precipitação, solo etc.). Entretanto, áreas distantes geograficamente, como as encontradas por Sztutman e Rodrigues (2002) em Pariquera-Açu, $\mathrm{SP}$, mostraram-se similares às de estudos realizados no Sul do Brasil. Tal fato induz a inferência de que condições ambientais similares (solo turfoso) podem também apresentar similaridade em sua composição, mantendo relação florística entre essas áreas (GUARINO; WALTER, 2005; SANTOS et al., 2007). Esses padrões podem influenciar na classificação da vegetação, ora baseada em aspectos florísticos (espécies dominantes e frequentes), ora em aspectos ambientais (SOUZA et al., 2003; LIMA et al., 2009).

Revista Árvore, Viçosa-MG, v.37, n.2, p.299-309, 2013 
As formações da planície costeira, restingas e florestas brejosas, dadas as suas condições ambientais extremas, são consideradas formações marginais da Floresta Atlântica. Mesmo assim, de sua composição tomam parte espécies originalmente atlânticas, o que pode indicar ampla plasticidade ecológica dessas espécies (SCARANO, 2002, 2006), ou processos de adaptação. A adaptação é evidenciada pela participação estrutural de espécies como M. multiflora e I. pseudobuxus, citadas como ocorrentes preferencialmente em substrato turfoso (KINDEL, 2002; DORNELES; WAECHTER, 2004).

Scudeller et al. (2001) atribuíram o conceito de "nicho estreito" às espécies restritas a determinados hábitats, onde participam com maior abundância, em relação a outros locais, como observado em $M$. multiflora. Uma hipótese baseada em ocupação de nichos na estruturação comunitária é que a comunidade é resultado da capacidade individual das espécies em sobreviver (adaptações fisiológicas), competir e reproduzir, com sucesso, em diferentes condições ambientais, vindo a modificar a composição e estrutura de comunidades ao longo de gradientes (VASQUEZ; GIVNISH, 1998).

A restrição de nicho é caracterizada na seletividade de espécies imposta por fatores limitantes, no caso deste estudo o substrato. Sztutman e Rodrigues (2002) evidenciaram essa seletividade pela acentuada redução na riqueza específica em florestas sobre turfa profunda (saturação hídrica), turfa rasa (saturação moderada) e morrote (solo bem drenado), atribuindo à seletividade de espécies em direção às formações hidricamente saturadas. Essa seletividade salientada pelos referidos autores pode ser atribuída ao caráter limitante imposto pelo ambiente (substrato) à comunidade, ressaltando a grande capacidade de adaptação das espécies a essas condições. Tal situação é reforçada pelas baixas correlações obtidas pela CCA, evidenciada na baixa variância explicada e ausência de gradientes ambientais atuando na distribuição das espécies.

As correlações de luminosidade implicam relação que pode não refletir um gradiente causal na distribuição de espécies nessa formação, pois os estudos desenvolvidos em florestas tropicais enfatizam a luminosidade como um recurso que atua no recrutamento de novos indivíduos (DALLING et al., 1998; DALLING; HUBBELL, 2002), mas não possibilita conclusões ao se avaliar apenas o componente arbóreo adulto, como avaliado neste estudo.
$\mathrm{Na}$ área de estudo, os baixos valores obtidos para o pH têm sua relação com a natureza dos Organossolos que compõem a área de estudo, classificados como Tiomórficos (SOUZA-JÚNIOR et al., 2001). Tais solos se caracterizam por apresentar um horizonte sulfúrico gerado pela oxidação de materiais sulfídricos (EMBRAPA, 1999), favorecendo a formação de ácido sulfúrico, que resulta em brusca redução do $\mathrm{pH}$ a valores inferiores a 3,5 (SOUZA-JÚNIOR et al., 2001).

Para as plantas, solos levemente ácidos podem levar à intemperização de rochas e tornar disponíveis nutrientes como $\mathrm{K}^{+}, \mathrm{Mg}^{+2}, \mathrm{Ca}^{+2} \mathrm{e} \mathrm{Mn}^{+2}$, da mesma forma que a acidez elevada pode também aumentar os níveis de íons como o $\mathrm{Al}^{+3}$, que, em concentrações elevadas, pode causar danos ao crescimento vegetal, em especial da raiz, bem como impedir a absorção de outros nutrientes. Em condições como a observada na área de estudo, as plantas estão submetidas a um estresse fisiológico, devido à condição anóxica imposta pela saturação hídrica e à toxidez provocada pelo alto teor de $\mathrm{Al}^{+3} \mathrm{e}$ valores elevados de $\mathrm{H}+\mathrm{Al}$.

A saturação hídrica favorece a retenção de íons $\mathrm{H}^{+}$e $\mathrm{Al}^{+3}$, que se unem fortemente às partículas do solo em oposição aos cátions, que tornam os solos ainda mais ácidos, inviabilizando a disponibilidade de cátions por lixiviação, evidenciados nos valores de V(GUREVITCH et al., 2009). Teixeira et al. (2008) relataram a influência da saturação hídrica na geração de variações edáficas (acidez), como variáveis proeminentes na distribuição de espécies ao longo de formações paludosas.

\section{CONCLUSÃO}

O fator edáfico tem importante papel na diferenciação das formações consideradas marginais da floresta atlântica (floresta brejosa neste estudo), demonstrado na baixa riqueza específica e na alta dominância ecológica. $\mathrm{O}$ substrato turfoso mostrou-se importante filtro ambiental na estruturação das comunidades, evidenciado na dissimilaridade com as formações brejosas em substratos de outra natureza. A análise de agrupamentos evidenciou que a proximidade geográfica ou a similaridade de ambientes podem levar à formação de comunidades similares. Ressalta-se a necessidade da conservação in situ, haja vista serem as florestas brejosas em substratos turfosos pouco conhecidas em seus aspectos florísticos e estruturais. 


\section{AGRADECIMENTOS}

À empresa Florestal S. A., pelo apoio e pela permissão para utilização de sua área; e aos revisores, pelas sugestões e comentários.

\section{REFERÊNCIAS}

\section{APG III - THE ANGIOSPERM PHYLOGENY}

GROUP. An update of the Angiosperm Phylogeny Group classification for the orders and families of flowering plants: APG III. Botanical Journal of the Linnean Society, v.162, n. 2, p. $105-121,2009$

CARVALHO, F. A. et al. Composição, riqueza e heterogeneidade da flora arbórea da bacia do rio São João, RJ, Brasil. Acta Botanica Brasilica, v.22, n.4, p.929-940, 2008.

DALLING, J. W. et al. Dispersal patterns and seed bank dynamics of pioneer trees in moist tropical forest. Ecology, v.79, p.564-578, 1998.

DALLING, J. W.; HUBBELL, S. P. Seed size, growth rate and gap microsite conditions as determinants of recruitment success for pioneer species. Journal of Ecology, v.90, n.3, p.557-568, 2002.

DILLENBURG, L. R. et al. Species composition and structure of a sandy coastal plain Forest in northern Rio Grande do Sul, Brazil. In: SEELIGER, U. (Ed.). Coastal plant communities of Latin America. New York: Academic Press, 1992. p.349-366.

DORNELES, L. P. P.; WAECHTER, J. L. Fitossociologia do componente arbóreo na floresta turfosa do Parque Nacional da Lagoa do Peixe, Rio Grande do Sul, Brasil. Acta Botanica Brasilica, v. 18, n.4, p.815-824, 2004.

DUFLOTH, J. H. et al. (Org). Estudos básicos regionais de Santa Catarina. Florianópolis: Epagri, 2005. CD ROM.

EMBRAPA - EMPRESA BRASILEIRA DE PESQUISA AGROPECUÁRIA. Centro Nacional de Pesquisa de Solos. Sistema brasileiro de classificação de solos. Rio de Janeiro: 1999.
FÉDOROFF, E. et al. Small-scale response of plant species to land-use intensification.

Agriculture, Ecosystems and

Environment, v.105, n.1, p.283-290, 2005.

FRAZER, G. W. et al. A comparison of digital and film fisheye photography for analysis of forest canopy structure and gap light transmission. Agricultural and Forest Meteorology v.109, n.4, p.249-263, 1999.

GUARINO, E. S. G.; WALTER, B. M. T.

Fitossociologia de dois trechos inundáveis de matas de galeria no Distrito Federal, Brasil. Acta Botanica Brasilica, v.19, n.3, p.431-442, 2005.

GUILHERME, F. A. G. et al. Horizontal and vertical tree community structure in a lowland Atlantic Rain Forest, Southeastern Brazil. Revista Brasileira de Botânica, v.27, n.4, p.725-737, 2004.

GUREVITCH, J. et al. Ecologia vegetal. Porto Alegre: Artmed, 2009. 592p.

KENT, M.; COKER, P. Vegetation description and analysis. New York: Wiley, 1992.363p.

KINDEL, A. Diversidade e estratégias de dispersão de plantas vasculares da floresta paludosa do Faxinal, Torres, RS. 2002. 102f. Tese (Doutorado em Botânica) Universidade Federal do Rio Grande do Sul, Porto Alegre, 2002.

LIMA, J. R. et al. Composição florística da floresta estacional decídua montana de Serra das Almas, CE, Brasil. Acta Botanica Brasilica, v.23, n.3, p.756-763, 2009.

LOPES, W. P. et al. Estrutura fitossociológica de um trecho de vegetação arbórea no parque estadual do Rio Doce - Minas Gerais, Brasil. Acta Botanica Brasilica, v.16, n.4, p.443456, 2002.

MORAES, D.; MONDIN, C. A. Florística e fitossociologia do estrato arbóreo e mata arenosa no balneário do Quintão, Palmares do Sul, Rio Grande do Sul. Pesquisas, Série Botânica, v.51, n.1, p.87-100, 2001.

Revista Árvore, Viçosa-MG, v.37, n.2, p.299-309, 2013 
MUELLER-DOMBOIS, D.; ELLENBERG, H. Aims and methods of vegetation ecology. New Jersey: The blackburn Press, 2002. 547p.

NEGRELLE, R. R. B. Composição florística e estrutura vertical de um trecho de Floresta Ombrófila Densa de Planície Quaternária. Hoehnea, v.33, n.3, p.261-289, 2006.

NEGRELLE, R. R. B. The Atlantic forest in the Volta Velha Reserve: a tropical rain forest site outside the tropics. Biodiversity and Conservation, v.11, n.5, p.887-919, 2003.

OLIVEIRA-FILHO, A. T.; FONTES, M. A. L. Patterns of floristic differentiation among atlantics forests in southeastern Brazil and the influence of climate. Biotropica, v.32, n.4b, p.793-810, 2000.

POTter, R.O. et al. Solos do Estado de Santa Catarina. Rio de Janeiro: Embrapa Solos. 2004. 713p. (Boletim de Pesquisa e Desenvolvimento, 46)

ROCHA, C. T. V. et al. Comunidade arbórea de um continuum entre floresta paludosa e de encosta em Coqueiral, Minas Gerais, Brasil. Revista Brasileira de Botânica, v.28, n.2, p.203-218, 2005.

RODRIGUES, R. R. A vegetação de Piracicaba e municípios de entorno. Circular Técnica IPEF, v. 189, p.1-20, 1999.

ROSSONI, M. G.; BAPTISTA, L. R. M. Composição florística da mata de restinga, Balneário Rondinha Velha, Arroio do Sal, RS, Brasil. Pesquisas, Série Botânica, v.45, p.115-131, 1994/1995.

SANTOS, R. M. et al. Riqueza e similaridade florística de oito remanescentes florestais no norte de Minas Gerais, Brasil. Revista Árvore, v.31, n.1, p.135-144, 2007.

SCARANO, F. R. Plant community structure and function in a swamp forest within the Atlantic rain forest complex: a synthesis. Rodriguésia, v.57, n.3, p.491-502, 2006.

Revista Árvore, Viçosa-MG, v.37, n.2, p.299-309, 2013
SCARANO, F. R. Structure, function and floristic relationships of plant communities in stressful hábitats marginal to the brazilian Atlantic Rainforest. Annals of Botany, v.90, p.517524, 2002.

SCHERER, A. et al. Florística e estrutura do componente arbóreo de matas de Restinga arenosa no Parque Estadual de Itapuã, RS , Brasil. Acta Botanica Brasilica, v.19, p.717-726, 2005.

SCUDELLER, V. V. et al. Distribution and abundance of arboreal species in the Atlantic Ombrophilous Dense Forest in southeastern Brasil. Plant Ecology, v.152, n.2, p.185-199, 2001.

SILVA, A. C. et al. Florística e estrutura da comunidade arbórea em fragmentos de floresta aluvial em São Sebastião da Bela Vista, Minas Gerais, Brasil. Revista Brasileira de Botânica, v.32, n.2, p.283-297, 2009.

SILVA, R. C. Florística, estrutura e aspectos da dinâmica da restinga arbórea no Parque Estadual de Itapeva, Torres, Rio Grande do Sul. 2010. 59f. Dissertação (Mestrado em Ciências Ambientais) - Universidade do Extremo Sul Catarinense, Programa de Pós-graduação em Ciências Ambientais, 2010.

SOUZA, J. S. et al. Análise das variações florísticas e estruturais da comunidade arbórea de um fragmento de floresta semidecídua às margens do rio Capivari, Lavras-MG. Revista Árvore, v.27, n.2, p.185-206, 2003.

SOUZA JÚNIOR, V. S. Propriedades químicas e manejo de solos tiomórficos da várzea do Rio Coruripe, Estado de Alagoas. Revista Brasileira de Ciência do Solo, v.25, n.4, p.811-822, 2001.

SZTUTMAN, M.; RODRIGUES, R. R. O mosaico vegetacional numa área de floresta contínua da planície litorânea, Parque Estadual da Campina do Encantado, Pariquera - Açu, SP. Revista Brasileira de Botânica, v.25, n.2, p.161-176, 2002. 
TEIXEIRA, A. P. et al. Tree species composition and environmental relationships in a Neotropical swamp forest in Southeastern Brazil. Wetlands Ecology and Management, v.16, n.6, p.451-461, 2008.

TEIXEIRA, A. P.; ASSIS, M. A. Caracterização florística e fitossociológica do componente arbustivoarbóreo de uma floresta paludosa no Município de Rio Claro (SP), Brasil. Revista Brasileira de Botânica, v.28, n.3, p.467-476, 2005.

TEIXEIRA, A. P.; ASSIS, M. A. Relação entre heterogeneidade ambiental e distribuição de espécies em uma floresta paludosa no município de Cristais Paulista, SP, Brasil. Acta Botanica Brasilica, v.23, n.3, p.843-853, 2009.

\section{TER BRAAK, C. J. F. CANOCO-a}

FORTRAN program for canonical community ordination by (partial) (detrended) (canonical) correspondence analysis and redundancy analysis. Wageningen: Groep Landbouwwiskeunde, 1987.

TER BRAAK, C. J. F. Ordination. In: JONGMAN, R. H. G. et al. (Ed.). Data analysis in community and landscape ecology. Cambrigde: Cambrigde University Press, 1995. p.91-173,
TER BRAAK, C. J. F.; ŠMILAUER, P. CANOCO Reference manual and canodraw for Windows user's guide: software for canonical community ordination (version 4.5). Microcomputer Power. Ithaca: 2002.

VÁZQUEZ, J. A.; GIVNISH, T. J. Altitudinal gradients in tropical forest composition, structure, and diversity in the Sierra de Manantlán.

Journal of Ecology, v.86, n.6, p.999-1020, 1998.

VELOSO, H. P.; KLEIN, R. M. As comunidades e associações vegetais da mata pluvial do sul do Brasil. I. As comunidades do mun. de Brusque, SC. Sellowia, v.9, n.1, p.81-235, 1957.

WAECHTER, J. L et al. Estrutura do componente arbóreo em uma floresta subtropical de planície costeira interna. In: SIMPÓSIO DE ECOSSISTEMAS BRASILEIROS, 5., 2000, Vitória. Anais... Vitória: 2000. p.92-112. v.3. (Publicação ACIESP, 109-III)

WAECHTER, J. L.; JARENKOW, J. A. Composição e estrutura do componente arbóreo nas matas turfosas do Taim, Rio Grande do Sul. Biotemas, v.11, n.1, p.45-69, 1998. 